\title{
Numerical Simulation of Two-Phase Flow Behavior in Venturi Scrubber by Interface Tracking Method
}

\author{
Naoki Horiguchi ${ }^{a, b *}$, Hiroyuki Yoshida a and Yutaka Abe ${ }^{\mathrm{b}}$ \\ a Japan Atomic Energy Agency, 2-4, shirakata, Tokai-mura, Naka-gun, Ibaraki-ken 319-1195, Japan \\ ${ }^{b}$ University of Tsukuba, 1-1-1, Tennodai, Tsukuba-shi, Ibaraki-ken, 305-8577, Japan
}

\begin{abstract}
From the viewpoint of protecting a containment vessel of light water reactor and suppressing the diffusion of radioactive materials from a light water reactor, it is important to develop the device which allows a filtered venting of contaminated high pressure gas. In the filtered venting system that used in European reactors, so called Multi Venturi Scrubbers System is used to realize filtered venting without any power supply. This system is able to define to be composed of Venturi Scrubbers (VS) and a bubble column. In the VS, scrubbing of contaminated gas is promoted by both gas releases through the submerged VS and gas-liquid contact with splay flow formed by liquid suctioned through a hole provided by the pressure difference between inner and outer regions of a throat part of the VS. However, the scrubbing mechanism of the self-priming VS including effects of gas mass flow rate and shape of the VS are understood insufficiently in the previous studies. Therefore, we started numerical and experimental study to understand the detailed two-phase flow behavior in the VS. In this paper, to understand the VS operation characteristics for the filtered venting, we performed numerical simulations of two-phase flow behavior in the VS. In the first step of this study, we perform numerical simulations of supersonic flow by the TPFIT to validate the applicability of the TPFIT for high velocity flow like flow in the VS. In the second step, numerical simulation of two-phase flow behavior in the VS including selfpriming phenomena. As the results, dispersed flow in the VS was reproduced in the numerical simulation, as same as the visualization experiments.
\end{abstract}

Keywords: Filtered venting, Venturi scrubber, Two-phase Flow, Numerical simulation

\section{Introduction}

In the wake of Fukushima Daiichi nuclear disaster, countermeasures against severe accidents in nuclear power plants are an urgent need. In particular, from the viewpoint of protecting the containment vessel of a light water reactor and suppressing diffusion of the radioactive materials from the light water reactor, it is important to install filtered venting devices to release high pressure pollutant gas to the atmosphere with elimination the radioactive materials in the gas.

Filtered venting systems with Venturi Scrubbers and a pool, called as Multi Venturi Scrubber System (MVSS), Filtered Containment Venting System (FCVS) and so on, are used to realize

*Corresponding author. Tel.: +81 29853 5498;

fax: +81 29853 5498; email: s1430215@u.tsukuba.ac.jp 
filtered venting without any power supply in European and Japanese reactors (Lindau 1988, Rust et al. 1995). These systems are composed of Venturi Scrubbers part, in which there are several or hundreds of the Venturi scrubbers, and a pool part. In these systems, all of the Venturi scrubbers are branched off from a vent line, which connects the containment vessel to the systems. The Venturi scrubber is a venturi tube with holes for suction at the throat part. In these systems, there are a dispersed flow in each Venturi scrubber and a bubbly flow in the pool part and the radioactive materials are eliminated through the gas-liquid interface from the pollutant gas to the liquid phase (Lindau 1988). In the Venturi scrubber, the dispersed flow is formed from the suctioned liquid from the pool through the holes by the pressure difference between inside and outside of the throat part (called self-priming (Lehner 1998)). The pressure difference caused hydraulic pressure from water surface of the pool to the holes and pressure drop by the convergent shape of the Venturi Scrubber.

W. Luangdilok et al. simulated about decontamination performance of a MVSS among a severe accident. He reported a Venturi scrubber has ineffective time windows for scrubbing the contaminated gas. It is caused by the high pressure gas and the suctioned liquid with low velocity, especially when the beginning of the scrubbing the large amount of the gas (Luangdilok 2009). N. Horiguchi observed the hydraulic behavior in a Venturi scrubber and confirmed that the high pressure and no suctioned liquid in it (he calls as self-priming suspension) under air-water conditions experimentally (Horiguchi et al. 2013).

H. Yoshida developed numerical simulation code TPFIT to simulate detailed two-phase flow behaviors in nuclear systems (Yoshida et al. 2004). H. Yoshida, et al. simulated rising bubble behavior under accelerating conditions by the code and validated it with the previous experimental date (Yoshida et al. 2014, Mizuno et al. 2012). T. Suzuki et al. simulated jet breakup phenomena in liquid-liquid contact in BWR lower plenum by the TPFIT and validated about the hydraulic behavior (Suzuki et al. 2014, Saito et al. 2014).

In existing study, evaluation methods for the scrubbing performance of the Venturi scrubber were developed. However, actual hydraulic behavior in it is too complicated, the previous evaluation was not validated the hydraulic behavior and studied the effect of differences between the simulated hydraulic behavior and an actual one on the performance of the Venturi scrubber. To develop a validated evaluation method for the scrubbing performance, it is important to develop detailed evaluation method for the hydraulic behavior in the Venturi scrubber. To simulate the complicated hydraulic behavior we consider to use analysis code TPFIT (Yoshida et al. 2004).

Then, an objective of this paper is to validate the hydraulic behavior simulated by TPFIT. As approaches, we conducted the analysis code by TPFIT under single-phase conditions in lab scale and validated its hydraulic behavior with previous studies. In addition, we perform a two-phase flow simulation for more realistic conditions.

\section{Numerical Simulation Method}

\subsection{Outline of the TPFIT}

This paragraph is written based on the report (Yoshida et al. 2004) to show you the outline of the TPFIT. 
The TPFIT was developed by Japan Atomic Energy Agency to simulate detailed two-phase flow behaviors in nuclear systems (Yoshida et al. 2004). Governing equations used in the TPFIT consist of averaged (mixed) mass, momentum, and energy conservation equations for compressible fluid and transport equations for the mass of both phases as shown in the following.

Mass:

$$
\frac{D \rho}{D t}=-\rho \frac{\partial u_{i}}{\partial x_{i}}
$$

where $u$ denotes the velocity component and $x$ denotes the coordinate. Density $\rho$ is calculated with the help of the following equation using the density and the volume fraction $f$ of the gas and liquid phases:

$$
\rho=\rho_{l} f_{l}+\rho_{g} f_{g}, \quad f_{g}=1-f_{l} .
$$

Momentum:

$$
\frac{D u_{i}}{D t}=-\frac{1}{\rho} \cdot \frac{\partial p}{\partial x_{i}}+\frac{1}{\rho} \cdot \frac{\partial \tau_{i j}}{\partial x_{j}}+g_{i}+\sigma_{i},
$$

where $p$ denotes the static pressure, $\tau$ denotes the shear stress, and $g$ and $\sigma$ are the acceleration due to gravity and surface tension, respectively.

Energy:

$$
\frac{D e}{D t}=-\frac{p}{\rho} \cdot \frac{\partial u_{i}}{\partial x_{i}}+\frac{1}{\rho} \cdot \frac{\partial}{\partial x_{i}}\left(\lambda \frac{\partial T}{\partial x_{i}}\right)
$$

where $e$ denotes the internal energy, $\lambda$ denotes the thermal conductivity, and $T$ denotes the temperature. In the evaluation of the volume fraction, in order to improve the precision of the analysis, the masses of both gas and liquid phases are evaluated.

Mass of both phases:

$$
\frac{D \rho_{m} f_{m}}{D t}=-\rho_{m} f_{m} \frac{\partial u_{i}}{\partial x_{i}}
$$

where subscript $m$ denotes the gas or liquid phase. The mass and the volume fraction of liquid or gas are evaluated using the advanced interface tracking method developed by Yoshida et al. (Yoshida et al. 2004).The two-phase capability, interface deformation and jet breakup, was validated (Yoshida et al. 2004, Suzuki et al. 2014). 


\subsection{Numerical Conditions for Single-Phase Flow Simulation}

In this paper, in order to validate the basic applicability of the TPFIT code for the flow in a Venturi scrubber, a numerical analysis of single-phase flow in the Venturi scrubber was performed. Figure 1 shows the computational domain of the numerical simulation modeled the Venturi scrubber used by N. Horiguchi et al. (Horiguchi et al. 2013). Its width ( $x$ direction), depth ( $y$ direction), and height ( $z$ direction) were set to be 10.6, 8.0, and $160.2 \mathrm{~mm}$, respectively. A ratio of the cross-section area between the inlet and the throat is 4.24. Its total number of numerical grids was $158,400(=30 \times 32 \times 165)$. Gird size at throat part in $x$ and $y$ directions is $0.25 \mathrm{~mm}$ and $0.5 \mathrm{~mm}$ in $z$ direction.

An outflow boundary condition was used on the top surface of the computational domain. An inflow boundary condition is used in the bottom surface of the domain. In the condition, the pressure, the temperature and the inlet velocity are set as constant. At wall surfaces, so-called "nonslip wall” boundary condition is used. The inlet and initial air were at room temperature (300 K) and atmospheric pressure $(0.1 \mathrm{MPa})$. Pressure at the outlet was set to atmospheric pressure (0.1MPa).

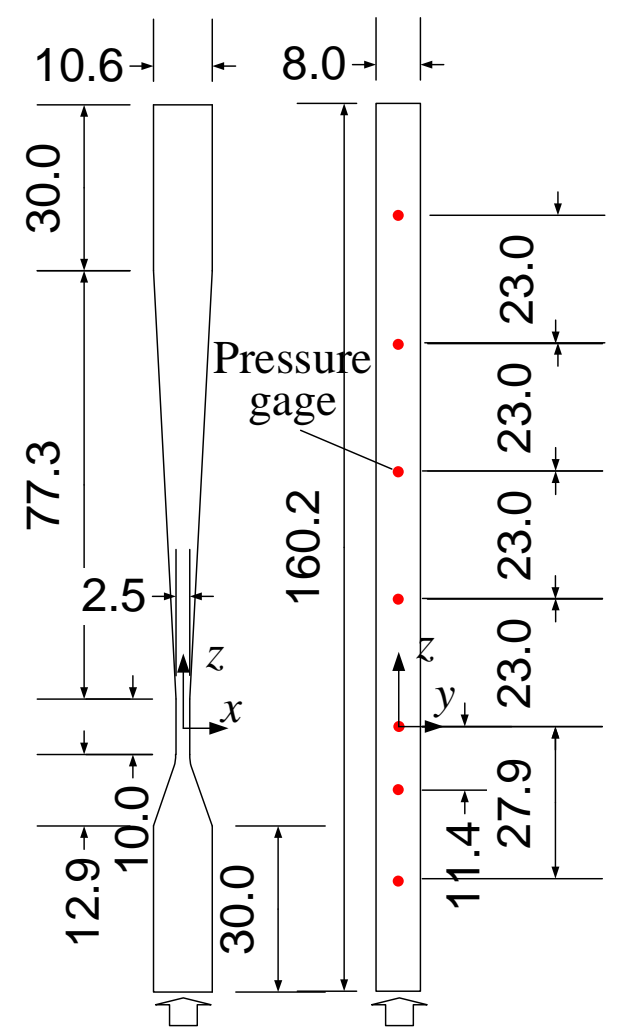

Fig. 1 Analytical domain for singlephase flow simulation. red symbol is pressure measurement points in the experiments (Horiguchi et al. 2013).

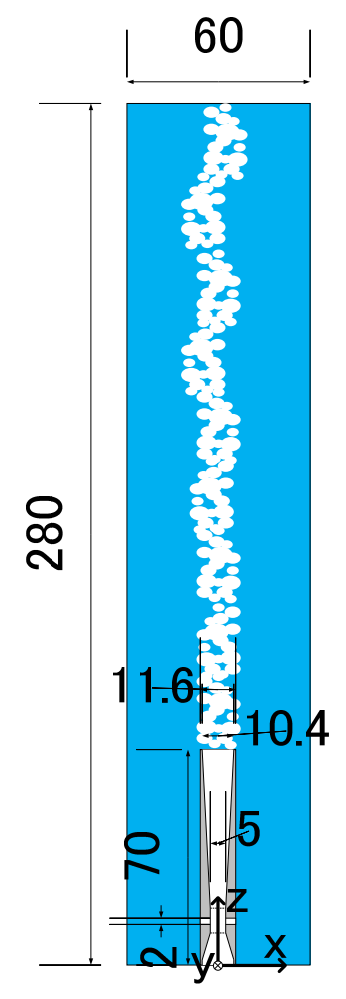

(a) Whole Region

Fig. 2 Analytical domain for two-phase flow simulation.

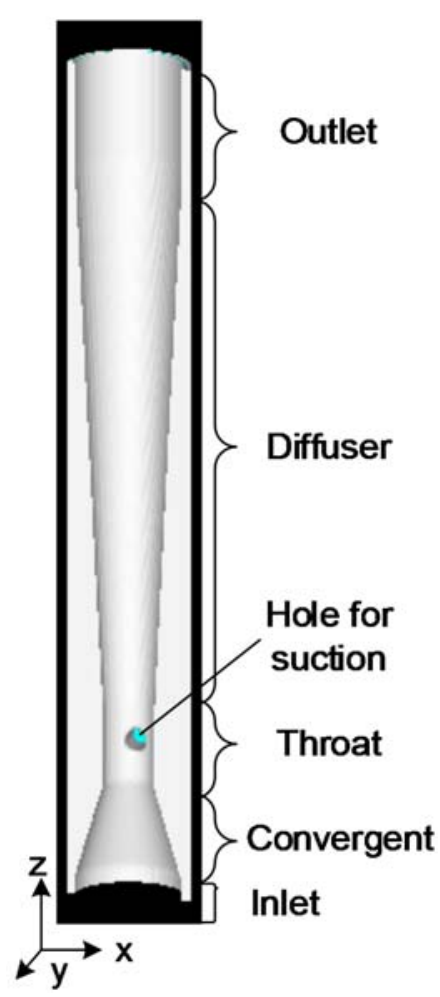

(b) Detail of VS 
In this paper, three cases of numerical simulation of single-phase flow were performed. In these simulations, inlet air velocities were set at $45.2,66.8$ and $88.4 \mathrm{~m} / \mathrm{s}$. In the experiments, pressure was measured at 7 points as shown in Fig.1. Predicted pressure distributions were compared with measured results in Sec. 3.1.

\subsection{Numerical Conditions for Two-Phase Flow Simulation}

In this paper, in order to validate the basic applicability of the TPFIT code for the flow in a Venturi scrubber and predict detailed two-phase flow characteristic in the Venturi scrubber, a numerical analysis of two-phase flow in the Venturi scrubber was performed. Figure 2 shows the computational domain of the numerical simulation. Its width ( $x$ direction), depth ( $y$ direction), and height ( $\mathrm{z}$ direction) were set to be 60.0, 60.0, and $280.0 \mathrm{~mm}$, respectively. Its total number of numerical grids was 4,494,400 $(=106 \times 106 \times 400)$. The Venturi scrubber is put at the center of the bottom surface of the domain.

A geometry of the Venturi scrubber is shown in Fig.2 (b). It has the inlet, the convergent, the throat, the diffuser and the outlet part as same as a Venturi tube. In addition, in the throat part, there are two oppositely arranged holes for suction. In the Venturi scrubber, the height is set to be $70.0 \mathrm{~mm}$. The diameters of the inlet, the throat, the outlet and the holes are set to be 10.4, 5.0, 10.4 and $2.0 \mathrm{~mm}$. A ratio of the cross-section area between the inlet and the throat is 4.32. An opened angle of the diffuser is set to be 6 degrees not to have a burble flow if gas flows in a Venturi tube.

An outflow boundary condition was used on the top surface of the computational domain. An inflow boundary condition is used in the bottom surface of the domain just inside of the Venturi scrubber. In the condition, the pressure, the temperature and the inlet velocity are set as constant. At wall surfaces, so-called "non-slip wall” boundary condition is used.

In the numerical simulation, air and water are used as two components of working fluids. The computational domain is initially filled with water except inside of the Venturi scrubber. The water and the gas in the Venturi scrubber are at room temperature $(300 \mathrm{~K})$ and atmospheric pressure $(0.1$ $\mathrm{MPa}$ ). The inlet velocity of the Venturi scrubber is set to $30 \mathrm{~m} / \mathrm{s}$ and the inlet pressure is set to atmospheric pressure.

\section{Results and Discussions}

\subsection{Single-Phase Flow Simulation}

Figures 3 and 4 show snapshots of pressure and axial distribution in single phase flow. Highest pressure values were appeared in the inlet section of the Venturi scrubber. In the convergent part, pressure was rapidly decreasing accordance with acceleration of the fluid, In the throat part, pressure was gradually decreasing by shear stress acting on the fluid. In the diffuser part, pressure was increasing, and, in the outlet part of the Venturi scrubber, pressure values were almost constant and equal to the atmospheric pressure. In the case of high velocity $\left(j_{g}=88.4 \mathrm{~m} / \mathrm{s}\right)$, pressure was largely decreasing near exit of the throat part, and minimum values were observed in the diffuser part. In this region, axial velocity was increasing. Its main cause is thought to be effects of 
compressibility of fluid. Related to pressure and axial distribution, although some fluctuation was observed, the change in the horizontal plane was relatively small.

Figure 5 shows predicted axial pressure distributions and pressure values measured at 7 axial location in the experiment. Predicted axial pressure distributions were evaluated by time and horizontal plane averaging. Averaging time range is from 0.0075 to $0.01 \mathrm{~s}$. At the exit of the Venturi scrubber, pressure was fixed at the atmospheric value $(0.1 \mathrm{MPa})$, and pressure was increasing from the minimum value to the atmospheric pressure in the diffuser part. In the case of high velocity, near the exit of throat part, decreasing pressure was relatively large. Therefore, pressure in the throat part was higher than the atmospheric pressure. If inlet pressure of hole for suction is smaller than the pressure in the throat part, self-priming suspended. Measured pressure values were almost same as predicted values except the throat part pressure of low and middle velocity cases. This value is strongly affected by the inlet flow rate of gas, and small differences between inlet conditions and experimental conditions were the main cause of these differences. The difference in pressure predictions upstream of the throat for medium and high velocity cases caused by the difference of the inlet pressure is considered. For example, in case of the high velocity condition, the averaged velocity at inlet boundary is $88.4 \mathrm{~m} / \mathrm{s}$ and pressure is $0.1 \mathrm{MPa}$, however, in the experimental result, the pressure is $0.2 \mathrm{MPa}$ and superficial velocity in inlet part is $88.4 \mathrm{~m} / \mathrm{s}$.

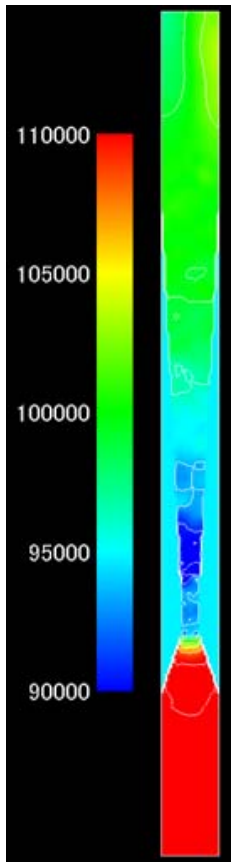

(a) $j_{g}=45.2 \mathrm{~m} / \mathrm{s}$ Fig.3 Pressure Flow ( $\mathrm{t}=0.01 \mathrm{~s})$
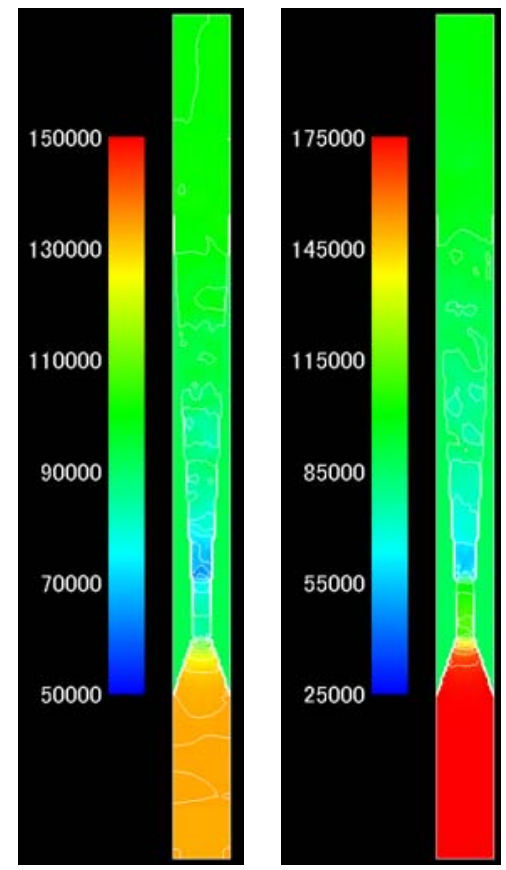

(b) $j_{g}=66.8 \mathrm{~m} / \mathrm{s}$ (c) $j_{g}=88.4 \mathrm{~m} / \mathrm{s}$ Distribution in Single-Phase (1)

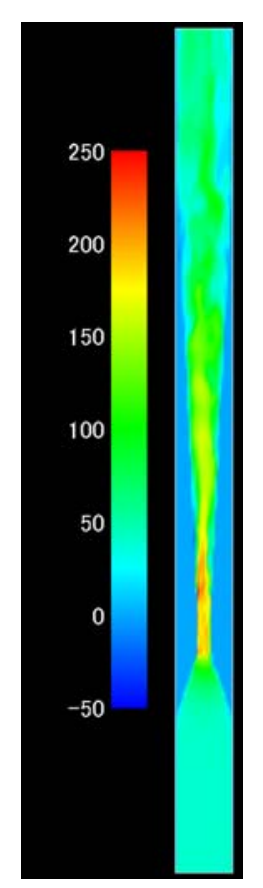

(a) $j_{g}=45.2 \mathrm{~m} / \mathrm{s}$
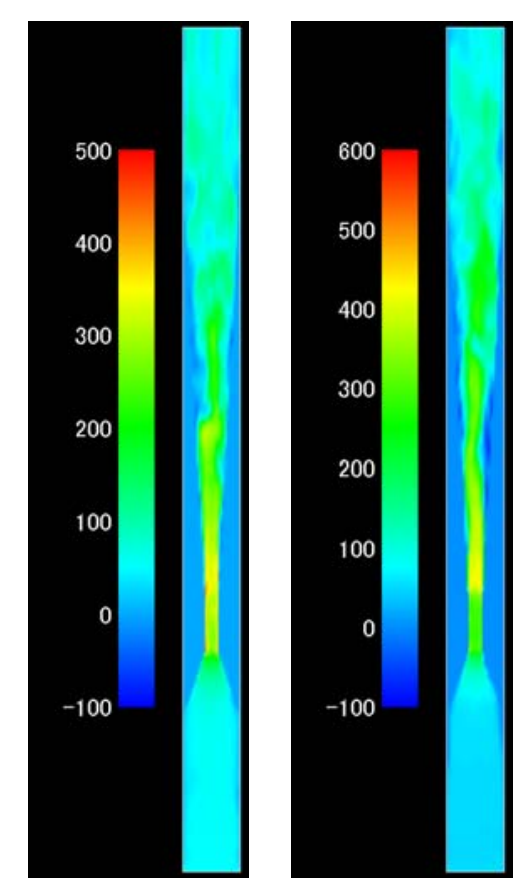

(b) $j_{g}=66.8 \mathrm{~m} / \mathrm{s}$ (c) $j_{g}=88.4 \mathrm{~m} / \mathrm{s}$ Fig.4 Axial Velocity Distribution in SinglePhase Flow $(\mathrm{t}=0.01 \mathrm{~s})$ 


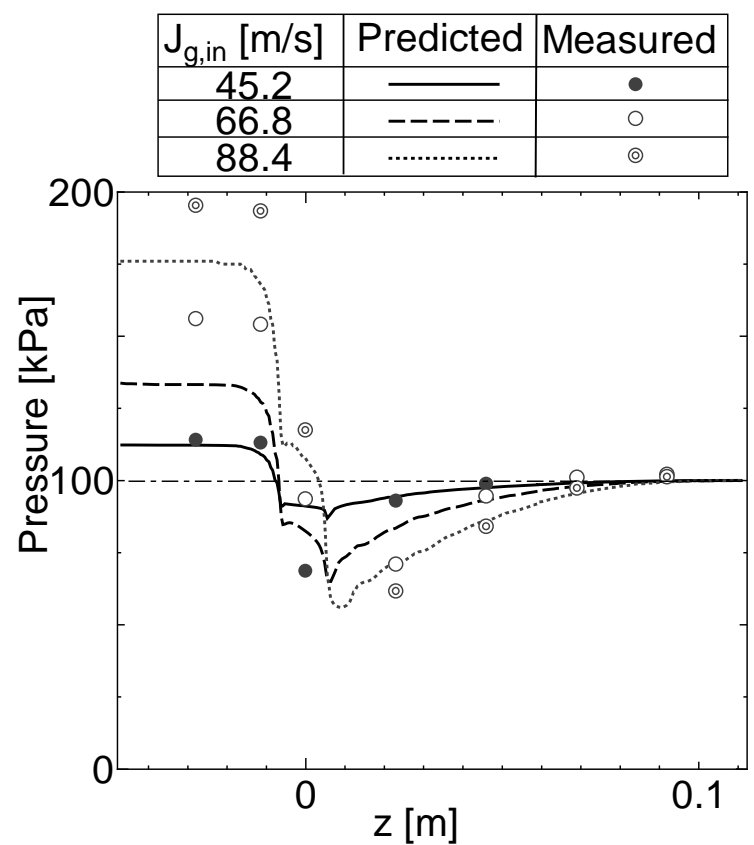

Fig.5 Axial Pressure Destruction

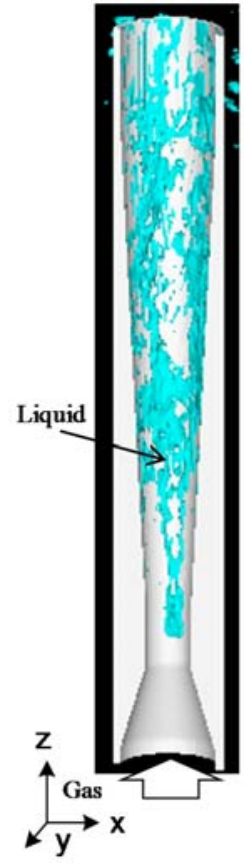

(a) $3 \mathrm{D}$ view

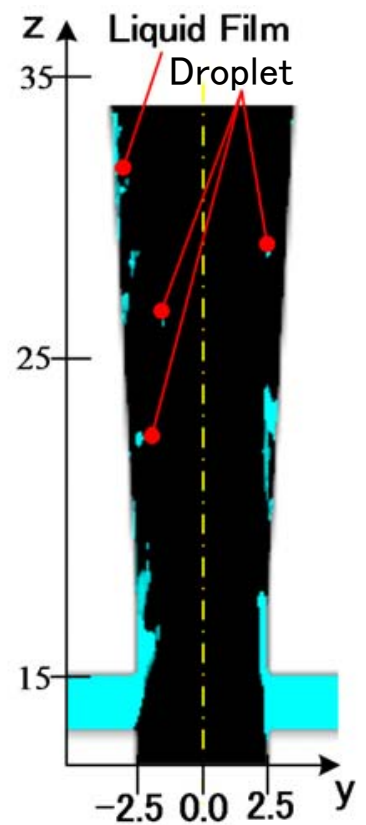

(b) Cross-section view of the center

Fig.6 Snapshots of the volume ratio in the VS with the annular dispersed flow ( $\mathrm{t}=15 \mathrm{~ms})$.

\subsection{Two-Phase Flow Simulation}

The numerical analysis of the circular Venturi scrubber was carried out. We observed hydraulic behaviors of the analysis result in the Venturi scrubber in terms of volumetric fraction, pressure distribution and velocity distribution.

Figure 6 shows an example of the result and a gas-liquid two-phase flow in the $y$-z plane of the center of the Venturi scrubber when the time is 15 ms during the analysis. In Fig. 6 (a), an interface is defined as an isosurface of the volume fraction of water and air is equal to 0.5 . The gas flows upward from the bottom to the top of the Venturi scrubber. In the Venturi scrubber, liquid is observed. Because of, on the initial condition, no liquid and the gas flow direction in the Venturi scrubber, the liquid is suctioned through the holes is considered.

In Fig. 6 (b), a cross-section in the x-z plane of the center of the Venturi scrubber is defined as a contour of the volume fraction of the water and air is over 0.5 . Near the hole, a part of the liquid forms, waving films and droplets is observed. From this result, the gas-liquid flow in the Venturi scrubber is an annular dispersed flow is confirmed and atomization of liquid due to be stripped by the gas flow in the throat and diffuser part is considered which reported by M. Lehner (Lehner 1998) as liquid column break up near the holes or by M. Ishii (Ishii et al. 1989) as entrainment stripped by the gas flow from the liquid film. The pressure and velocity distribution in $\mathrm{x}-\mathrm{z}$ plane of the center of the Venturi scrubber are shown in Fig. 7 (a) and Fig. 7 (b) respectively, when the time were 15 ms. In Fig. 7 (a), a color contour was defined as pressure from $90 \mathrm{kPa}$ to $120 \mathrm{kPa}$. The region of $90 \mathrm{kPa}$ and under was blue and the region of $120 \mathrm{kPa}$ and over was red. In Fig. 7 (b), a color contour was defined as the amplitude of the velocity in the z-axis direction from $0 \mathrm{~m} / \mathrm{s}$ to 


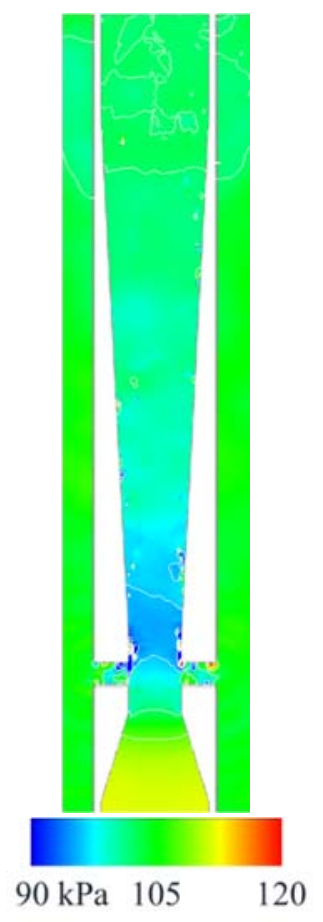

(a) Pressure

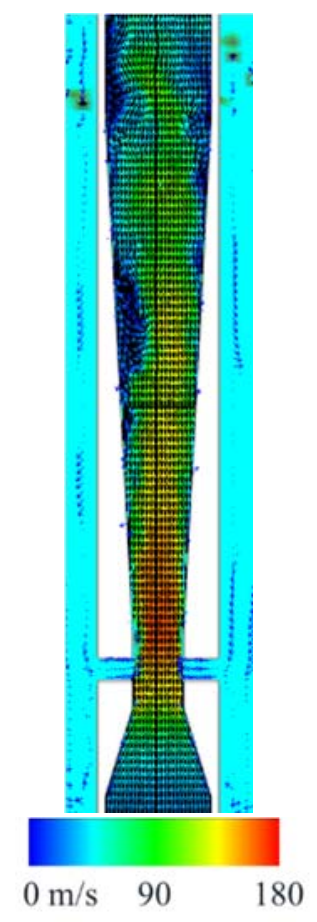

(b) Velocity

Fig. 7 Snapshots of the pressure and velocity distribution in the VS ( $\mathrm{t}=15 \mathrm{~ms})$.

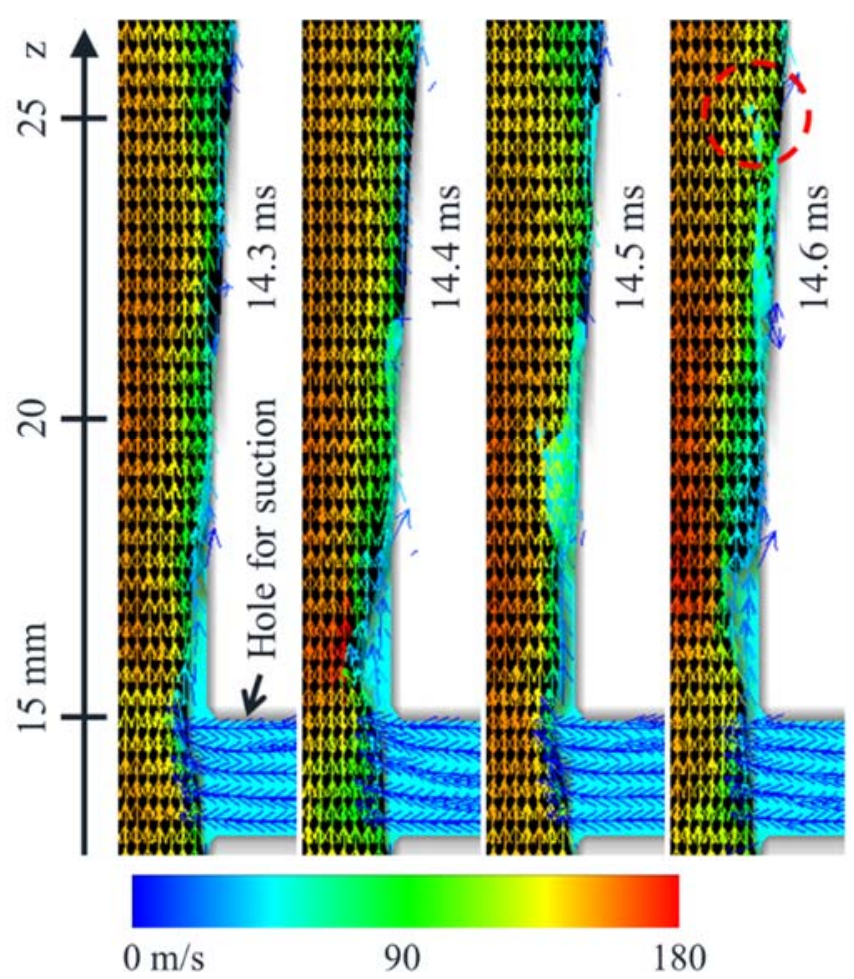

Fig. 8 Snapshots of the atomization behavior near the hole for suction.

$180 \mathrm{~m} / \mathrm{s}$. The region of $0 \mathrm{~m} / \mathrm{s}$ was blue and the region of $180 \mathrm{~m} / \mathrm{s}$ and over was red. If an ideal gas flow in a venturi tube, the pressure decreases and the velocity increases along with decreasing the cross-section area of the convergent part and vice versa. In the convergent part, the pressure decreased and the velocity increased and on the contrary, in the diffuser part, the pressure increased and the velocity decreased like the gas flows in a venturi tube. However, in diffuser part, the flow has disturbance and burble flow near the inner wall nevertheless the open angle of the diffuser part was set not to have burble if gas flows in a venturi tube. In consideration of the annular dispersed flow, the flow in the Venturi scrubber has the disturbance and burble flow by the effect of the liquid film and droplets is considered.

By the way, we focused on throat part and observed pressure in the throat is lower than outside of the Venturi scrubber and the liquid flows into the Venturi scrubber through the hole. From these results, the self-priming phenomena occurs because of pressure balance between the inside and the outside of the throat is confirmed.

To observe the hydraulic behavior in detail, we focused on some of the atomization phenomena in throat and diffuser part. Figure 8 shows the atomization phenomena near the hole for suction when the times are 14.3 - 14.6 ms. The color contour was defined as same as Fig. 7 (b). The suctioned liquid flowed for the downstream as a film flow is observed.

Then, on the film, a wave grew and stripped as a droplet by a gap of a relative velocity between the gas and the liquid film. As one of the atomization in a Venturi scrubber, a liquid column breakup reported by P.K. Wu, et al. (Wu et al. 1995) is not observed. On the other hand, the 


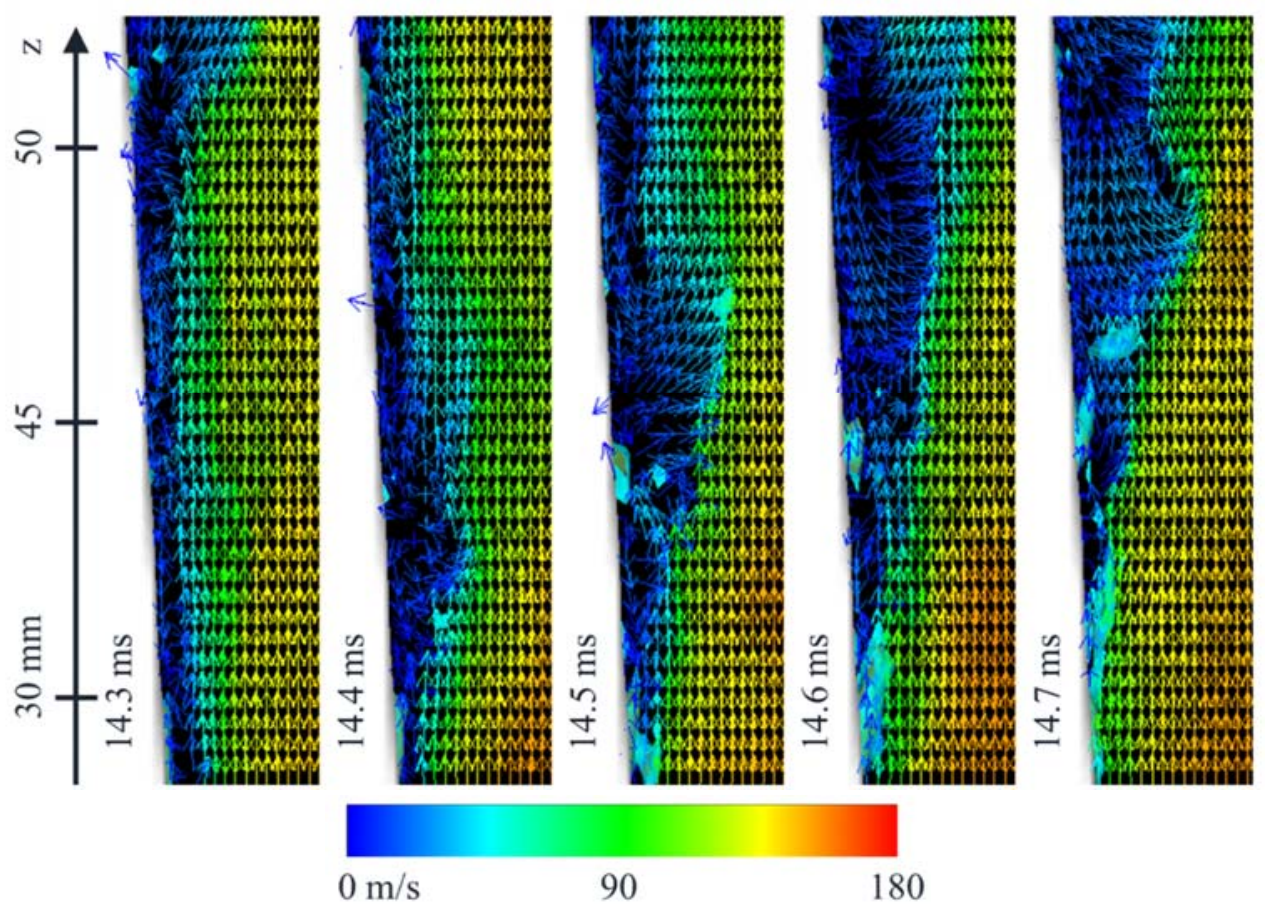

Fig. 9 Snapshots of the atomization behavior in the diffuser part when the times are 14.3-14.7 ms.

atomization is considered as the one by shearing-off of roll wave crests of the liquid film on the wall reported by M. Ishii (Ishii et al. 1989). However, it is considered these two atomization can be observed by change the inlet velocity of the Venturi scrubber because M. Lehner (Lehner 1998) reported change of atomization behavior by the velocity and some of the atomization are similar to the one of P.K. Wu, et al. (Wu et al. 1995) and M. Ishii, et al. (Ishii et al. 1989) respectively.

Figure 9 shows other atomization phenomena in the diffuser part when the times are 14.3 14.7 ms. It color contour was defined as same as Fig. 7 (b). In the first, a burble flow of gas has a stagnation point was observed at $14.3 \mathrm{~ms}$. Then, the burble flow moved upward and a liquid film flows into the burble flow. The film crushed to a backflow of gas in the burble flow and a droplet generated by the film removed off the wall at $14.5 \mathrm{~ms}$. The atomization is observed repeatedly over the time. The atomization with a burble flow of gas is similar to the atomization with a burble flow of two-phase flow reported by N. Horiguchi (Horiguchi et al. 2013).

As a result, the hydraulic behaviors in the Venturi scrubber simulated by TPFIT were observed and compared with results of previous studies. In the future works, we need to estimate quantitatively the hydraulic behaviors, droplet diameter, thickness of the liquid film and the wave size on the film, and validate the analyzed results quantitatively. Based on these studies, we will consider the number of grids needed to simulate an actual Venturi scrubber for filtered venting and simulate it. 


\section{CONCLUSIONS}

To validate the applicability of the TPFIT to two-phase flow in the Venturi scrubber, we conducted a numerical simulation by TPFIT under air-water conditions in laboratory scale and validated its hydraulic behavior with previous studies qualitatively. As results, we obtained these followings.

The self-priming phenomena occur because of pressure balance between the inside and the outside of the throat is confirmed. The flow in the Venturi scrubber is similar to the one in a Venturi tube except it has the disturbance and burble flow by the effect of the liquid film and droplets is considered. Some of the atomization phenomena in the Venturi scrubber were validated qualitatively by comparison with previous studies.

\section{NOMENCLATURE}

$\begin{array}{ll}e & : \text { energy } \\ f & : \text { Volume ratio of liquid } \\ g & : \text { Acceleration of gravity }\left[\mathrm{m} / \mathrm{s}^{2}\right] \\ p & : \text { Pressure }[\mathrm{Pa}] \\ t & : \text { Time }[\mathrm{s}] \\ u & : \text { Speed }[\mathrm{m} / \mathrm{s}] \\ x & : \text { Coordinate }[\mathrm{m}] \\ \lambda & : \text { Thermal conductivity }\left[\mathrm{W} / \mathrm{m}^{2} \mathrm{~K}\right] \\ \rho & : \text { Density }\left[\mathrm{kg} / \mathrm{m}^{3}\right] \\ \sigma & : \text { Acceleration by surface tension }\left[\mathrm{m} / \mathrm{s}^{2}\right] \\ \tau & : \text { Shear stress }\left[\mathrm{N} / \mathrm{m}^{2}\right]\end{array}$

\section{Greek letters}

g : represents gas phase

l : represents liquid phase

m : represents gas or liquid phase

i : cell number

Horiguchi, N., et al., 2013. Research and Development of Self-Priming Venturi Scrubber for Filter Venting: Preliminary Analysis and Observation of Hydraulic Behavior in Venturi Scrubber, 21th International Conference on Nuclear Engineering, ICONE21-16287.

Ishii, M., et al., 1989. Droplet entrainment correlation in annular two-phase flow, Int. J. Heat Mass Transfer, Vol.32 No.10, pp. 1835-1846.

Lehner, M., 1998. Aerosol Separation Efficiency of a Venturi Scrubber Working in Self-Priming Mode, Aerosol Sci. Technol., Vol. 13, pp. 389-402.

Lindau, L., 1988. FILTRA-MVSS, A system for reactor accidents mitigation, J. Aerosol Sci., Vol. 19 No. 7, pp. 1389-1392. 
Luangdilok, W., 2009. Modeling of the Venturi Scrubber for the FILTRA-MVSS System, NUCLEAR INSIGHTS, Vol. 3, No. 3, pp. 7-10.

Mizuno, K., et al., 2012, Development of prediction technology of two-phase flow dynamics under earthquake acceleration (5)- measurement of bubble deformation near wall under structure vibration -, Proceedings of 20th International Conference on Nuclear Engineering, ICONE20-54602.

Rust, H., et al., 1995. Pressure release of containments during severe accidents in Switzerland, Nuclear Engineering and Design, Vol. 157, pp. 337-352.

Saito, R., et al., 2014, Experimental study on breakup and fragmentation behavior of molten material jet in complicated structure of BWR lower plenum, Journal of Nuclear Science and Technology, Vol. 51, No. 1, pp. 64-76.

Suzuki, T., et al., 2014, Development of numerical evaluation method for fluid dynamics effects on jet breakup phenomena in BWR lower plenum, Journal of Nuclear Science and Technology, Vol. 51, No. 7-8, pp. 968-976.

Yoshida, H., et al., 2004. Investigation of Water-Vapor Two-Phase Flow Characteristics in a TightLattice Core by Large-Scale Numerical Simulation, (I); Development of a Direct Analysis Procedure on Two-Phase Flow with an Advanced Interface Tracking Method, J. Nucl. Sci. Technol., 3 (3), pp. 233-241.

Yoshida, H., et al., 2014, Development of prediction technology of two-phase flow dynamics under earthquake acceleration, Mechanical Engineering Journal, Vol. 1, No. 4, pp. 1-11.

Wu, P. K., et al., 1995. Effects of Initial Flow Conditions on Primary Breakup of Nonturbulent and Turbulent Round Liquid Jets, Atomization and Sprays, Vol. 5, No. 2, pp. 175-196. 